\title{
The Value Proposition of RFID Technology in Tall Prefabricated Timber Buildings
}

\author{
Perry Forsythe ${ }^{1}$, Alireza Ahmadian Fard Fini ${ }^{2 *}$, and Alireza Jalali Yazdi ${ }^{3}$ \\ ${ }^{1}$ Professor, School of Built Environment, University of Technology Sydney \\ ${ }^{2}$ Lecturer, School of Built Environment, University of Technology Sydney \\ ${ }^{3}$ PhD candidate, School of Built Environment, University of Technology Sydney \\ ${ }^{*}$ Corresponding author's e-mail: Alireza.Fini@uts.edu.au
}

\begin{abstract}
The full benefit of prefabricated timber systems in the construction of multi-story buildings depends on integration and efficiency in the upstream logistics and supply chain. The purpose of this research is therefore to determine the potential value that the use of Radio-Frequency Identification technology (RFID) can contribute to the prefabricated construction of timber, and to undertake the basic development of a RFID tracking model for this purpose. The methods used in this study not only build on the knowledge gained from previous literature, but also include interviews with industry experts, field trial design and field trials.

The research showed that the RFID tracking system's value proposition tends to be strongest where there are large scale and vertically integrated supply chains, logistics complexity between a limited number of discrete but partnered supply chain links and/or internal logistical complexity problems. Therefore, five distinct added value stages of RFID applications have been found in incoming delivery logistics, factory panel production, outgoing delivery logistics, on-site installation and third parties who can inspect the finished construction work. Application of RFID technology in prefabrication factory environments, where fixed readers can be used in predefined processes, was found promising. However, due to the temporary nature of the sites and the associated investment, the capacity for high automation levels is thought to be more limited on site.
\end{abstract}

\section{KEYWORDS}

Panelised prefabricated timber construction; RFID; Logistics; Supply chain management

\section{INTRODUCTION}

Poor productivity is often cited as being an ongoing problem in the construction industry (Bankwest, 2017). A method to deal with this issue, is utilizing prefabrication techniques to reduce on-the-jobsite construction uncertainty as well as construction time and costs (Li et al., 2014). Panelised prefabricated timber construction is a time-effective and productive construction method Forsythe et al. (2016). Studies on utilizing digital technologies to extend the advantages of this construction method, especially in terms of logistics and supply chain integration of prefabricated timber construction, therefore, are of great value in terms of productive construction.

When applying the above to prefabricated wood construction, the importance of logistics appears to increase with the scale of prefabrication operations. Since the manual assembly of many small objects on site, changes to handling a smaller number of large and value added prefabricated 
objects offsite, where care must be taken to ensure an efficient workflow from factory to site assembly (Forsythe et al., 2017). Concerning logistics management of prefabrication, RFID technology can potentially Identify and track large prefabricated panels in the entire process of manufacturing, transportation and assembly, and also, read through multiple layers of construction, thus allowing retrospective compliance checking/inspection of objects encapsulated within the construction (Forsythe et al., 2017).

The purpose of this research is to determine the potential value proposition that RFID offers the prefabricated timber construction and to undertake the basic development of a RFID tracking model. The proposed research can offer several advantages, including increasing the competitiveness of prefabricated timber/wood construction compared to traditional ones and improving the supply chain for medium- to large-scale logistics companies.

\section{LITERATURE REVIEW}

The use of advanced digital technology and offsite prefabrication are seen as the two key areas of construction productivity improvement (Global Construction Survey, 2016). Timber construction is well positioned to take advantage of both industry trends, as it has the potential to outstand over traditional building methods. RFID technology may play an important role in complementing this scenario. It is a type of auto-identification technology and refers to the process of indexing physical object information (such as wood panels and assemblies) and transferring information from the object to interested users using radio frequencies. The technology has gained momentum in various supply chains, including logistics and shipping (Ramanathan et al., 2014), retail (Loebbecke, 2005), Medical (Chao et al., 2007), and Mining (Mohd Khairul Nizam et al., 2016). There is currently a much lower level of uptake in construction compared to other industries. However, previous research has demonstrated the potential of RFID applications in areas such as labor management (Navon et al., 2003), construction tool tracking (Goodrum et al., 2006; Jaselskis Edward et al., 2003), pipe spool tracking (Jaselskis Edward et al., 2003; Song et al., 2006), machine maintenance records (Lu et al., 2011), prefabricated precast components (Demiralp et al., 2012) and logistics management of structural steel projects (Chin et al., 2008).

The unplanned, uncontrolled and dynamic events that typify construction projects create a major need for real-time information sharing among project participants and therefore justify the potential relevance of RFID technology (Majrouhi Sardroud, 2012). One example is (Chin et al., 2008), who examined the use of RFID in steel construction to identify production, delivery and on-site erection information, on the basis of a steel member unit. Their experiment demonstrated that the use of RFID offers more precise logistics and reduces the risk of lost materials and lost schedule time. Even more, the use of RFID for materials can improve low levels of information integration for materials, tool tracking and document management (Elghamrawy et al., 2010; Majrouhi Sardroud, 2012). (Lee et al., 2013) recognized similarly that tracking and providing realtime information on materials, tools, equipment, documents and information on the life cycle would facilitate construction processes. Another area of potential benefit with RFID technology is associated with cost coding for tagged objects (Lu et al., 2011).

Hinkka et al. (2013) suggest that if materials are RFID tagged, material tracking systems can provide information on the construction progress on site by simply walking with an RFID reader in hand. The information read from RFID tags would provide a more precise estimate of the percentage of completed work based on the quantity and type of goods delivered/installed, allowing for automated billing (Lee et al., 2013). RFID was successfully used in mining for the control of Personal Protective Equipment (PPE). For example, tags attached to the PPE identify 
when a worker passes through RFID reader gates stationed throughout the mine; the tag carries the vital information of the worker wearing the PPE and information related to the EPP, thereby ensuring that essential PPE components are worn by workers when they enter a mine (Mohd Khairul Nizam et al., 2016). In addition, in a case study, prefabricated concrete simulations were used to determine that cost savings of approximately 3 percent were possible on projects where prefabricated concrete panels were equipped with RFID tags before entering the supply chain (Demiralp et al., 2012).

The literature is, however, lean on functionality of RFID technology for the supply chain of prefabricated timber in the building industry. As supply chain processes vary with respect to different types of materials and projects, a separate research is required to scrutinize the feasibility of this technology in tall timber prefabricated buildings.

\section{METHODOLOGY}

To find the potential areas of benefit of RFID technology across the entire supply chain of prefabricated timber construction projects, and also its shortcomings and potential improvements, interviews were conducted with different parties involved in these projects. This involved a total of 17 interviews followed by content analysis of the data obtained. Of these, 10 Australian interviews were conducted with a view to understanding different prefabrication contexts, related supply chains and the relative need/interest in RFID technology within the Australian context. In general, efforts have been made to capture interviews covering different perspectives of RFID technology across the prefabricated supply chain of timber panels. These include timber design software companies that create and manipulate design information, timber manufacturers that carry out offsite production, logistics operations involving the transport of panels from one link in the supply chain to the next, construction contractors that install the prefabricated timber on site and must demonstrate compliance with the installed panels, property developers who may have a value-added use for the technology.

In order to ensure that interviewees had at least a basic understanding of the technology, an online briefing video was provided to them, prior to the interview. Interviewees were asked semi-open questions in a conversational style, most of which were taken face-to-face and took place at the workplace of the interviewee. Content analysis was then carried out on the data obtained:

1. Company background and explanation of work undertaken

2. Potential benefits of RFID technology in operations

3. Current procedures for the type and transfer of information/documentation

4. Problems that exist in the supply chain process in terms of tracking items

5. Current technologies used for tracking objects

6. Potential to reduce/simplify communications and traditional documentation

In addition to the Australian context, seven international interviews (with targeted companies in technically advanced timber-building industries encapsulating Scandinavia, Central Europe and Canada) were conducted to determine the use and application elsewhere as a fundamental means of benchmarking in Australia. These involved interviews and site visits at medium to large scale timber prefabrication plants.

\section{INTERVIEW FINDINGS}

The observations of the interviewees varied widely depending on the difference in their involvement in the supply chain. As an initial step, three identifiable types of information flows were found to exist: (i)Product information (i.e. product features relating to sustainability, quality, 
and compliance), (ii)Process dynamic information (i.e. active decision support of production/logistics/ construction process management) and (iii)Feedback during the service life of the end product (i.e. potential for information pertaining to building operation, inspection, durability and maintenance

The interview findings are edited by the authors to infer meaning and improve readability, and are summarized in Table 1.

Table 1. A summary of the interview findings

\begin{tabular}{|c|c|}
\hline The type of finding & Subject \\
\hline \multirow{2}{*}{$\begin{array}{l}\text { Application } \\
\text { requirements }\end{array}$} & Demand/desire to replace the existing system with more efficient ones \\
\hline & Early tagging, to retain information lineage throughout the processes \\
\hline \multirow{4}{*}{ Concerns } & $\begin{array}{l}\text { Cost vs. benefit of the technology, especially for companies with their } \\
\text { own well-developed systems }\end{array}$ \\
\hline & $\begin{array}{l}\text { RFID tags have low memory, thus, are not freestanding sources of } \\
\text { information }\end{array}$ \\
\hline & Information security issues, due to the link to the cloud database \\
\hline & $\begin{array}{l}\text { Limited ability to fully leverage the potential of the RFID technology, } \\
\text { because of project differentiations }\end{array}$ \\
\hline \multirow{3}{*}{ Business potentials } & $\begin{array}{l}\text { An interviewee saw benefits in matching the RFID technology with } \\
\text { their internal database and photogrammetry system }\end{array}$ \\
\hline & $\begin{array}{l}\text { Another interviewee saw considerable value in the RFID technology } \\
\text { for their business }\end{array}$ \\
\hline & $\begin{array}{l}\text { An interviewee identified potential benefits, if the technology could } \\
\text { allow property owners and managers to access information }\end{array}$ \\
\hline \multirow{3}{*}{ Oversees interviews } & Mostly use a QR code technology instead of RFID \\
\hline & $\begin{array}{l}\text { Applications in materials management concerning incoming delivery } \\
\text { and incoming inventory control }\end{array}$ \\
\hline & Applications in monitoring of panel fabrication production lines \\
\hline Sustainability & $\begin{array}{l}\text { Interviewees were not interested in applying RFID for sustainability } \\
\text { applications, since they see RFID as a cost saving technology }\end{array}$ \\
\hline
\end{tabular}

It must be noted that the interviewees who saw potential in employing RFID for their businesses were all involved in vertically integrated organizations. Hence, as will be discussed later, a vertically integrated organization was chosen as the case of this study.

\section{LAB TESTING AND FIELD DESIGN}

In the next stage, the researchers used basic laboratory tests to develop a preliminary setup around the design and use of RFID systems and developed a tailored RFID tracking system before testing in a real-world case scenario. It was recognized that the technology has to deal with two different environments, including factory and construction site contexts, requiring close- and long-range proximity between the reader and the tagged objects, respectively. The decision in this regard involves choosing among three RFID solutions: Low Frequency (LF), High Frequency (HF), and 
Ultra-High Frequency (UHF) technologies. A review of these options showed that UHF seemed to offer the greatest potential for the project's needs.

After a series of laboratory tests on the reading range and penetration through different material occlusions, a custom design for a specific case was developed based on results from both interviews and laboratory tests. The case study scenario was established with Strongbuild, a vertically integrated construction contracting company with a design office, offsite manufacturing facility and on-site contracting operations. They specialize in prefabricated CLT and timber framed construction solutions (including floor cassette panel fabrication, closed wall frame panels, roof trusses, interior fitout joinery, import and machining of CLT panels and manufacturing of bathroom pods). The company is a leader in large scale timber buildings including apartments, aged care, institutional and housing construction sectors. Fig. 1, is a schematic indicating the RFID system architecture.

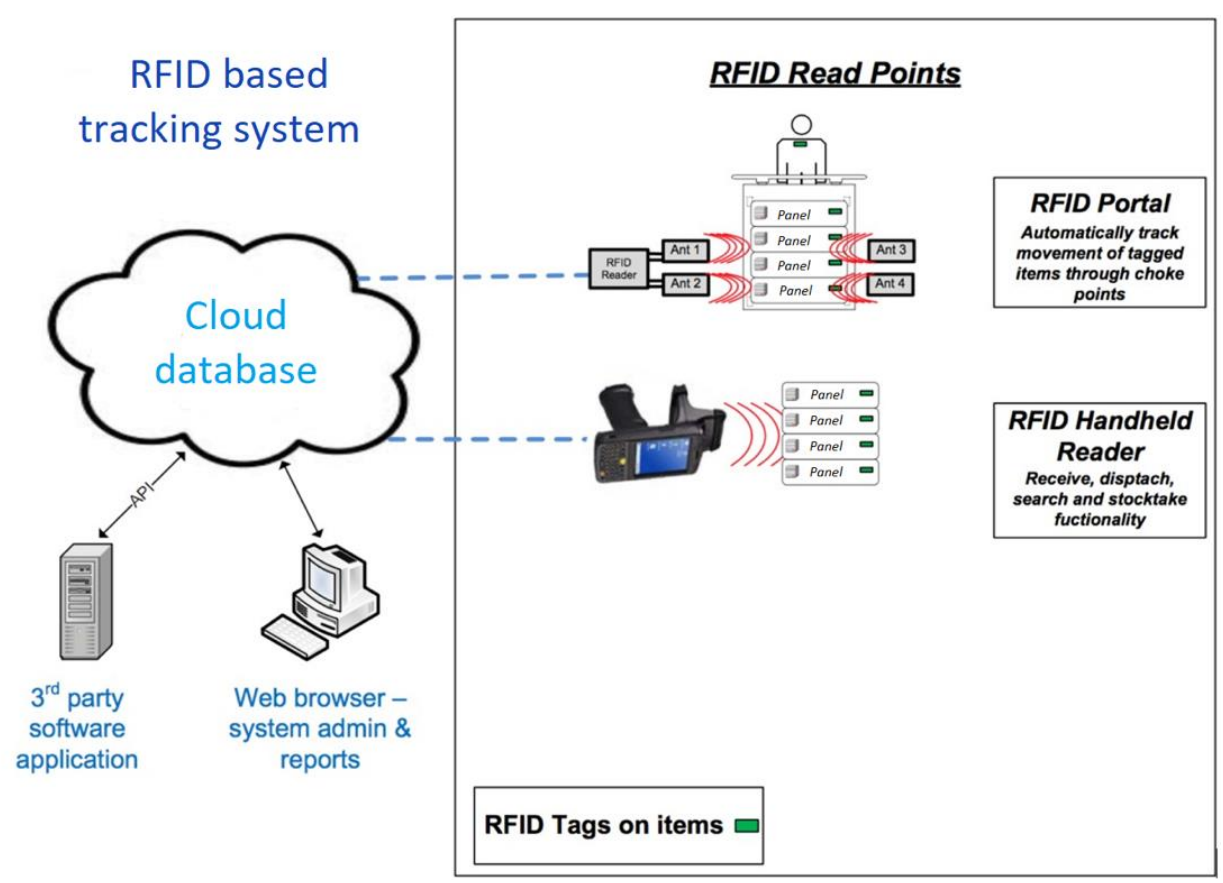

Figure 1. Components of an integrated RFID tracking system 
MOC SUMMIT / MAY 2019

Stream A: Cross-Laminated Timber Panels.

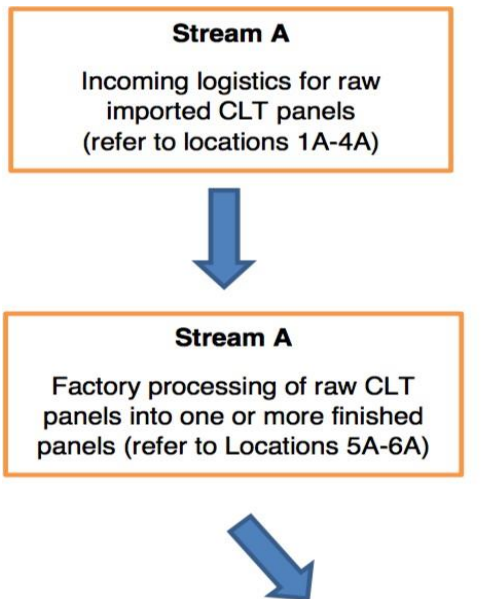

Stream B: Timber Framing Fabrication

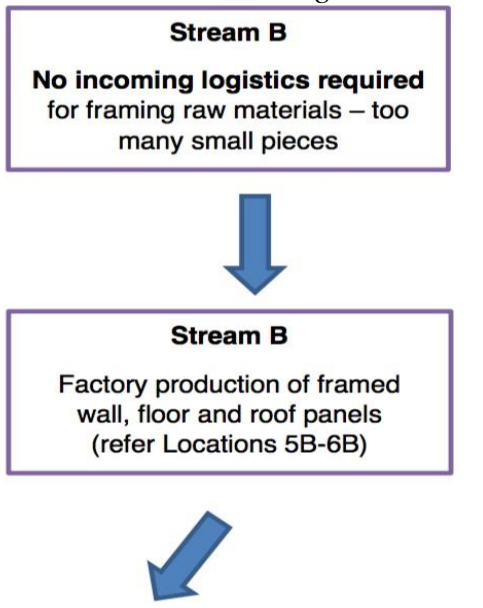

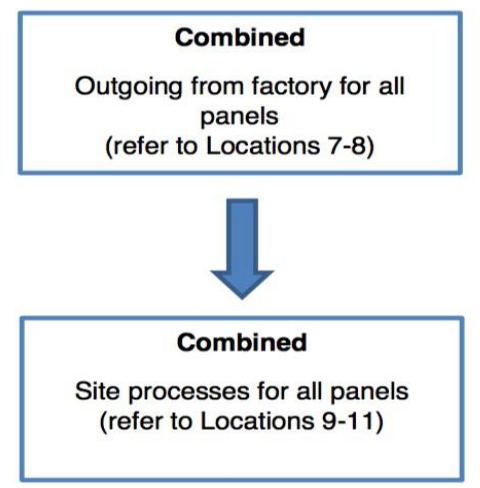

Locations Legend:

Arriving points

§ Location 1: Australian unpacking yard

$\S \quad$ Location 3: Factory's raw material storage area

$\S \quad$ Location 5: Production station

$\S \quad$ Location 7: Factory's finished product storage area

$\S \quad$ Location 9: Construction site stagging area

$\S \quad$ Location 11: In-situ
Leaving points

$\S \quad$ Location 2: Australian unpacking yard

$\S \quad$ Location 4: Factory's raw material storage area

$\S \quad$ Location 6: Production station

$\S \quad$ Location 8: Factory's finished product storage area

$\S \quad$ Location 10: Construction site stagging area

Figure 2. Overview of RFID reading locations for CLT (Stream A) and Framing fabrication (Stream B)

The arrangement of the over-arching process is shown in Figure 2 and acts as a high-level framework.

Four key phases of Strongbuild's interest in RFID technology, covering both CLT panels and framed panels, were identified. These phases included incoming delivery logistics for raw materials, factory production of panels, outgoing logistics of finished panels, site delivery and site installation. There were two variants of the main process for RFID application, each taking a different stream in terms of incoming delivery logistics and factory production, while their outgoing logistics and site installation are then combined into a common process:

- Raw CLT panels are imported from overseas. Such panels need to be tagged at the source (e.g. Binderholz in Austria) and tracking is then commenced once delivered to Australia. This includes delivery to the docks in Sydney, followed by shipment to a logistics storage 
facility (Enfield), and then dispatched to Strongbuild's storage area for incoming panels (Norwest factory). Once delivered, the raw panels are machined/cut into one or more finished panels in the factory in preparation for delivery to site.

- Framed panels are made in the Strongbuild factory from a kit of many smaller parts (noggings, studs, plates, insulation, OSB, plasterboard) that generally are not worth tagging, because it requires significant integration investment while the added value of tracking the production stage is little. Tagging is only worthwhile when the component kit is assembled into larger panel elements.

\section{CONCLUSIONS}

RFID technology essentially concerns real-time accessible information flows that remain with a particular product or object (in this case prefabricated wood panels) throughout a defined process. It is found that higher degrees of fragmentation in the supply chains of construction means that there are only small and/or individual benefits for each link, and therefore there is insufficient impetus to promote a strong value proposition for RFID technology. Conversely, the value proposition is strongest where there is an inclination towards integration across supply chain participants. Specific examples of this include:

1. Large scale and vertically integrated supply chains: The value proposition is strongest when a single company spans multiple connections within the supply chain.

2. Logistics between a limited number of large supply chain linked companies that work in an ongoing and integrated way: Here, the RFID technology seems to be most easily implemented in links pertaining to en masse suppliers of timber materials who work closely with the likes of large timber fabricators in a systematic manner.

3. Large scale internal logistics problems: This relates simply to internally dedicated tracking systems in the likes of large-scale fabrication companies dealing with repeated processes and products on a significant economy of scale.

The most promising area for further development and field testing is considered to be in the context of item 1 above i.e., Large scale and vertically integrated supply chains, as this seems to offer the best value proposition in the application of RFID technology to prefabricated timber construction.

\section{References}

Bankwest. (2017). Construction Industry Report.

Chao, C.-C., Yang, J.-M., \& Jen, W.-Y. (2007). Determining technology trends and forecasts of RFID by a historical review and bibliometric analysis from 1991 to 2005 . Technovation, 27(5), 268-279.

Chin, S., Yoon, S., Choi, C., \& Cho, C. (2008). RFID+4D CAD for Progress Management of Structural Steel Works in High-Rise Buildings. Journal of computing in civil engineering, 22(2), 74-89.

Demiralp, G., Guven, G., \& Ergen, E. (2012). Analyzing the benefits of RFID technology for cost sharing in construction supply chains: A case study on prefabricated precast components. Automation in construction, 24, 120-129.

Elghamrawy, T., \& Boukamp, F. (2010). Managing construction information using RFID-based semantic contexts. Automation in construction, 19(8), 1056-1066. 
Forsythe, P., Brisland, R., \& Sepasgozar, S. (2016). Measuring installation productivity on panellised and long span timber construction.

Forsythe, P., \& Carey, B. (2017). Application of RFID in the Prefabricated Timber Industry. Paper presented at the Australasian Universities Building Education Association Conference 2017.

Global Construction Survey. (2016). Retrieved from https://assets.kpmg.com/content/dam/kpmg/xx/pdf/2016/09/global-construction-survey2016.pdf

Goodrum, P. M., McLaren, M. A., \& Durfee, A. (2006). The application of active radio frequency identification technology for tool tracking on construction job sites. Automation in construction, 15(3), 292-302.

Hinkka, V., \& Tätilä, J. (2013). RFID tracking implementation model for the technical trade and construction supply chains. Automation in construction, 35, 405-414.

Jaselskis Edward, J., \& El-Misalami, T. (2003). Implementing Radio Frequency Identification in the Construction Process. Journal of construction engineering and management, 129(6), 680-688.

Lee, J. H., Song, J. H., Oh, K. S., \& Gu, N. (2013). Information lifecycle management with RFID for material control on construction sites. Advanced Engineering Informatics, 27(1), 108119.

Li, Z., Shen, G. Q., \& Xue, X. (2014). Critical review of the research on the management of prefabricated construction. Habitat international, 43, 240-249.

Loebbecke, C. (2005). RFID technology and applications in the retail supply chain: The early metro group pilot. BLED 2005 Proceedings, 42.

Lu, W., Huang, G. Q., \& Li, H. (2011). Scenarios for applying RFID technology in construction project management. Automation in construction, 20(2), 101-106.

Majrouhi Sardroud, J. (2012). Influence of RFID technology on automated management of construction materials and components. Scientia Iranica, 19(3), 381-392.

Mohd Khairul Nizam, M., Mohd Remy Rozainy, M. A. Z., \& Norlia, B. (2016). Applications of Radio Frequency Identification (RFID) in Mining Industries. IOP Conference Series: Materials Science and Engineering, 133(1), 012050.

Navon, R., \& Goldschmidt, E. (2003). Monitoring labor inputs: automated-data-collection model and enabling technologies. Automation in construction, 12(2), 185-199.

Ramanathan, R., Ramanathan, U., \& Ko, L. W. L. (2014). Adoption of RFID technologies in UK logistics: Moderating roles of size, barcode experience and government support. Expert Systems with Applications, 41(1), 230-236.

Song, J., Haas Carl, T., \& Caldas Carlos, H. (2006). Tracking the Location of Materials on Construction Job Sites. Journal of construction engineering and management, 132(9), 911918. 